\title{
Disorders of the Aorta and Aortic Valve in Connective Tissue Diseases
}

\author{
Bogna Grygiel-Górniak ${ }^{1}$ (D) Mary-Tiffany Oduah ${ }^{1} \cdot$ Abdulbaril Olagunju $^{1} \cdot$ Michal Klokner $^{1}$
}

Published online: 19 June 2020

(C) The Author(s) 2020

\begin{abstract}
Purpose of Review The incidence of aortic valve disease in inherited connective tissue disorders is well documented; however, recent studies have only begun to unravel the pathology behind this association. In this review, we aim to describe the etiology, clinical manifestations, management, and prognosis of aortic and aortic valvular disorders that co-exist in a variety of connective tissue diseases. An extensive literature review was performed in PubMed. Articles from 2008 to 2018 were included for review. Predetermined search terms used in PubMed include "aortic manifestation of connective tissue diseases" and "aortic valve disorders in rheumatologic disease."

Recent Findings Manifestations of aortic valve disease in the context of connective tissue disorders include valvular stenosis, regurgitation, and/or thoracic aortic aneurysms. Both inherited and inflammatory connective tissue disorders contribute to aortic valve damage with increased susceptibility associated with specific gene variants.

Summary Anti-inflammatory and immunosuppressive therapies have demonstrated beneficial results in Marfan's syndrome, Behcet disease, rheumatoid arthritis, ankylosing spondylitis, and systemic sclerosis, often leading to remission. Yet, such therapy is less effective in other disorders compared to alternative treatments such as surgical intervention. Additionally, regular echocardiographic studies should be recommended to those suffering from these disorders, especially those at higher risk for cardiovascular involvement.

Given the rates of relapse with immunosuppressants, even following aortic valve replacement, further studies are needed to determine if certain dosing and/or combinations of immunosuppressants could be given to those diagnosed with connective tissue diseases to prevent progression of aortic valve involvement.
\end{abstract}

Keywords Aortic valve diseases $\cdot$ Connective tissue diseases $\cdot$ Diagnosis $\cdot$ Treatment

\section{Introduction}

Aortic and aortic valve disorders manifesting as aortic valve sclerosis, stenosis, insufficiency, bicuspid aortic valve, aortitis, and aortic aneurysms occur in the setting of rheumatic

This article is part of the Topical Collection on Valvular Heart Disease

Bogna Grygiel-Górniak

bgrygiel@ump.edu.pl

Mary-Tiffany Oduah

dobezemd@gmail.com

Abdulbaril Olagunju

ab.dapoola@gmail.com

Michal Klokner

mihaw_18@hotmail.com

1 Department of Rheumatology and Internal Diseases, Poznan University of Medical Sciences, Poznan, Poland diseases. There is a paucity of recent studies, which seek to unravel the underlying mechanisms for increased cardiovascular disease risk in rheumatologic diseases. In this review, we aim to describe the etiology, clinical manifestations, management, and prognosis of aortic valvular disorders that are present in a variety of connective tissue diseases.

Manifestations of aortic valve disease in the context of connective tissue disorders include valvular stenosis, regurgitation, and/or thoracic aortic aneurysms (Tables 1 and 2). Both inherited and inflammatory connective tissue disorders contribute to aortic valve damage with increased susceptibility associated with specific gene variants. There is insufficient knowledge regarding the underlying mediators, and thus appropriate immunotherapy to target specific cytokines in order to dampen the inflammatory response. For example, in Marfan's syndrome, TGF- $\beta$ has been documented to play a crucial role and thus presents a therapeutic target. Ultimately, the goal of such therapies would be the induction of 
Table 1 Connective tissue diseases and their manifestations in the aorta and aortic valve

\begin{tabular}{ll}
\hline $\begin{array}{l}\text { Aortic disorders and aortic valve } \\
\text { manifestations }\end{array}$ & Connective tissue diseases \\
\hline Aortic valve regurgitation & • Ankylosing spondylitis \\
& $\begin{array}{l}\text { - Churg-Strauss syndrome } \\
\text { - Behcet disease }\end{array}$ \\
& - Ehlers-Danlos syndrome \\
& - Primary antiphospholipid \\
& syndrome \\
& - Systemic sclerosis \\
& - Primary antiphospholipid \\
Aortic valve stenosis & syndrome-related bioprosthetic \\
& valve stenosis \\
Aortic valve stenosis and & - SLE \\
regurgitation & - Sjogren syndrome \\
Aortic valve thickening & - Rheumatoid arthritis \\
Dilation of aortic root and/or & - Granulomatosis with polyangiitis \\
ascending aorta; dissecting & Marfan's syndrome \\
thoracic aortic aneurysms; aortic & \\
valve regurgitation &
\end{tabular}

remission without the need for valve replacement, which is associated with inherent risk.

Despite demonstrating promising results in the treatment of Ehlers-Danlos syndrome (EDS), surgical intervention of the aortic valve has been associated with many complications, including the need for recurring operations in Behcet disease and ankylosing spondylitis and a high mortality and morbidity rate in systemic lupus erythematosus (SLE).

Given that patients experience relapse when placed on immunosuppressants, even following aortic valve replacement, further studies are needed to determine if certain dosing regimens and/or combinations of immunosuppressants are helpful in preventing progression to aortic valve involvement.

\section{Aortic Valve Manifestations in Rheumatic Diseases}

\section{Rheumatoid Arthritis}

Rheumatoid arthritis (RA) is a chronic, autoimmune, inflammatory disorder that primarily affects synovial joints, with a prevalence of $0.53-0.55 \%$ in the USA $[1 \bullet \bullet, 2]$. The disease is progressive, eroding cartilage and bone, resulting in joint deformities, severe disability, and ultimately early mortality. Although the central pathology of RA pertains to the synovium of diarthrodial joints, many non-articular organs are affected in chronic cases, including the heart. [3] One systematic review reported a $48 \%$ increased risk for CVD in patients diagnosed with RA, a $60 \%$ increased risk of $\mathrm{CV}$ death, and a reduced life expectancy of 3 to 10 years, compared to the general population. [4] Additionally, the pattern of CVD in RA patients differs from the general population, as they are more likely to develop silent ischemic heart disease, develop heart failure with increased morbidity and mortality [5]. Additional markers of vascular disease in RA include aortic valve thickening, isolated valvular insufficiency, aortic root abnormalities, and other valvular lesions. [6] Fig. 1 illustrates underlying mechanisms leading to valvular lesions in RA.

Moreover, the most distinctive valvular lesions are rheumatoid granuloma within valve leaflets, occurring as a result of nonspecific inflammatory and fibrotic reactions at the base of the valve that causes thickening and calcification [7]. Furthermore, when inflammation cannot be adequately controlled in such conditions, fibrosis is observed in the valvular base, followed by calcification and finally valvular lesion. [8] Given that the suppression of RA-associated inflammation has been shown to not only decrease lipid levels but also reduce $\mathrm{CV}$ events, anti-inflammatory medication has demonstrated beneficial results as a treatment method [9]. One study found that the use of anakinra, an IL-1 blocker, improved CV function in RA patients as early as $3 \mathrm{~h}$ after administration of the first dose, a result that was sustained after 30 days of regular use [10॰]. Furthermore, anti-TNF biologics have become fairly standard for treating the $\mathrm{CV}$ manifestations of RA. Vizzardi et al. reported that a 1 -year treatment with anti-TNF- $\alpha$ drugs significantly reduced systemic inflammation, aortic wall stiffness, and the overall activity of the disease [11].Future studies are needed to better understand the effect of treatment on the course of cardiovascular complications related to rheumatoid arthritis.

\section{Systemic Lupus Erythematosus and Antiphospholipid Syndrome}

Systemic lupus erythematosus (SLE) is a chronic inflammatory disease, which affects all organ systems [12•]. It is classified as a systemic autoimmune disease of unknown etiology, with a prevalence of $20-70$ per 100,000 that is 6 times greater in women than men, and a peak onset between 15 and 40 years of age [13-15]. SLE is characterized by over-reactive and auto-reactive $\mathrm{T}$ cells, which distort normal cytokine production, resulting in increased inflammation and multi-organ tissue damage. Furthermore, B cells are also over-reactive, producing excessive amounts of autoantibodies, which form immune complexes that ultimately deposit into various organs and disrupt normal tissues functions [16]. The heart is an example of such an organ, given the high prevalence of cardiovascular disease in SLE of over 50\%. [17]

Valvular abnormalities are quite prevalent in SLE patients, including aortic valve regurgitation, which was reported to be one of the most common valvular impairments observed. [18] One of the most prevalent cardiac manifestations of SLE is 
Table 2 Aortic valve changes in certain vasculitis

\begin{tabular}{|c|c|c|c|c|}
\hline $\begin{array}{l}\text { Name of } \\
\text { vasculitis }\end{array}$ & Takayasu arteritis & Granulomatosis with polyangiitis & $\begin{array}{l}\text { Churg-Strauss } \\
\text { syndrome }\end{array}$ & Behcet disease \\
\hline $\begin{array}{l}\text { Type of } \\
\text { vasculitis }\end{array}$ & $\begin{array}{l}\text { Large vessel } \\
\text { arteritis }\end{array}$ & $\begin{array}{l}\text { ANCA-associated small vessel } \\
\text { vasculitis }\end{array}$ & $\begin{array}{l}\text { ANCA-associated small } \\
\text { vessel vasculitis }\end{array}$ & Various vessel vasculitis \\
\hline $\begin{array}{l}\text { Aortic } \\
\text { involvement }\end{array}$ & $\begin{array}{l}\text { Aortic } \\
\quad \text { regurgitation }\end{array}$ & $\begin{array}{l}\text { Aortic regurgitation (rarely aortic } \\
\text { stenosis) }\end{array}$ & $\begin{array}{l}\text { Mainly aortic } \\
\text { regurgitation }\end{array}$ & $\begin{array}{l}\text { Aortic regurgitation } \\
\text { Aneurysms } \\
\text { Pseudoaneurysms } \\
\text { Aortic rupture } \\
\text { Stenotic lesions (brachiocephalic artery) }\end{array}$ \\
\hline $\begin{array}{l}\text { Characteristic of } \\
\text { aortic valve } \\
\text { changes }\end{array}$ & $\begin{array}{l}\text { - Secondary to } \\
\text { dilation of the } \\
\text { aortic root } \\
\text { - Normal valvular } \\
\text { cusps in } \\
\text { echocardiogra- } \\
\text { phy shows } \\
\text { - Aneurysm can } \\
\text { be present }\end{array}$ & $\begin{array}{l}\text { - Thickened cusps of the aortic } \\
\text { valve } \\
\text { - May be the only sign of relapse in } \\
\text { GPA } \\
\text { - The onset: at the time of diagnosis } \\
\text { or few years after diagnosis and } \\
\text { correlates with elevated } \\
\text { PR3-ANCA } \\
\text { - Chronic or acute manifestations } \\
\text { (e.g., the perforation of the cusps } \\
\text { of the aortic valve) }\end{array}$ & $\begin{array}{l}\text { The valve is dense and } \\
\text { thick due to fibrosis } \\
\text { and the inflammatory } \\
\text { reaction }\end{array}$ & $\begin{array}{l}\text { Aortic regurgitation } \\
\text { - The most common valvular pathology } \\
\text { - Aneurysm } \\
\text { - Elongation and prolapse of aortic cusps } \\
\text { - Vegetation like lesions } \\
\text { Aortic valve regurgitation } \\
\text { - Can be secondary to aneurysm of the } \\
\text { ascending aorta due to vasculitis } \\
\text { - Normal or fibrosed cusps of the valves } \\
\text { - Annulus dilatation } \\
\text { - Cusp fenestration and fusion }\end{array}$ \\
\hline $\begin{array}{l}\text { Histopathologic } \\
\text { findings }\end{array}$ & $\begin{array}{l}\text { - Disrupted elastic } \\
\text { fibers in the } \\
\text { media } \\
\text { - Granuloma } \\
\text { - Marked collagen } \\
\text { deposition in } \\
\text { the adventitial }\end{array}$ & $\begin{array}{l}\text { - Granulomatous inflammation } \\
\text { - Polymorphonuclear } \\
\text { microabscesses (differentiate } \\
\text { with infective endocarditis) } \\
\text { - Foci of necrosis } \\
\text { - All findings located in the central } \\
\text { layer of the valve }\end{array}$ & $\begin{array}{l}\text { - Fibrosis and } \\
\text { inflammation }=> \\
\text { dense and thick valve } \\
\text { - Valve leaflets } \\
\text { infiltrated by } \\
\text { eosinophils, } \\
\text { lymphocytes and } \\
\text { plasma cells } \\
\text { - Necrotizing } \\
\text { granulomas }\end{array}$ & $\begin{array}{l}\text { Lymphoplasmacytic infiltrates, neutrophils, } \\
\text { histiocytes, eosinophils and occasional giant } \\
\text { cells, myxoid degeneration, focal necrosis, } \\
\text { and fibrotic thickening }\end{array}$ \\
\hline Treatment & $\begin{array}{l}\text { - Aortic valve } \\
\text { replacement } \\
\text { - Aortic root } \\
\text { replacement }\end{array}$ & $\begin{array}{l}\text { - Immunosuppressive therapy used } \\
\text { in GPA - No impact on the } \\
\text { development of aortic } \\
\text { regurgitation } \\
\text { - Increasing dose of } \\
\text { cyclophosphamide => Slows } \\
\text { down the progression of aortic } \\
\text { regurgitation }\end{array}$ & $\begin{array}{l}\text { Improvement after } \\
\text { - Prednisolone } \\
\text { - Cyclophosphamide } \\
\text { - Aortic valve } \\
\text { replacement if relapse } \\
\text { is present }\end{array}$ & $\begin{array}{l}\text { - Aortic valve replacement } \\
\text { - Pharmacologic treatment: anticoagulants, } \\
\text { immunosuppressive therapy, colchicine }\end{array}$ \\
\hline
\end{tabular}

Libman-Sacks endocarditis with 1-4 mm large, verrucous vegetations present on either side of the aortic and mitral valves [19].

Elevated levels of antiphospholipid antibodies (aPL) are present among SLE patients with antiphospholipid syndrome (APS) often presenting as an arterial or venous thrombosis. Multiple studies have discovered aPL immune complexes, fragments of complements, and fibrin and platelets within valvular vegetations in SLE patients presenting with
Libman-Sacks endocarditis [19]. This is thought to occur as a result of aPL immune complexes depositing on valvular surfaces, ultimately leading to direct valvular damage through thrombotic or inflammatory mechanisms (Fig. 2). Moreover, one study found that increased levels of aPL antibodies, specifically higher than $40 \mathrm{U} / \mathrm{mL}$, were significantly associated with increased risk of heart valve disease (HVD), further supporting this theory [19]. Additionally, it was observed that valve lesions in Libman-Sacks endocarditis patients were
Fig. 1 Overview of aortic valve disorders in rheumatoid arthritis

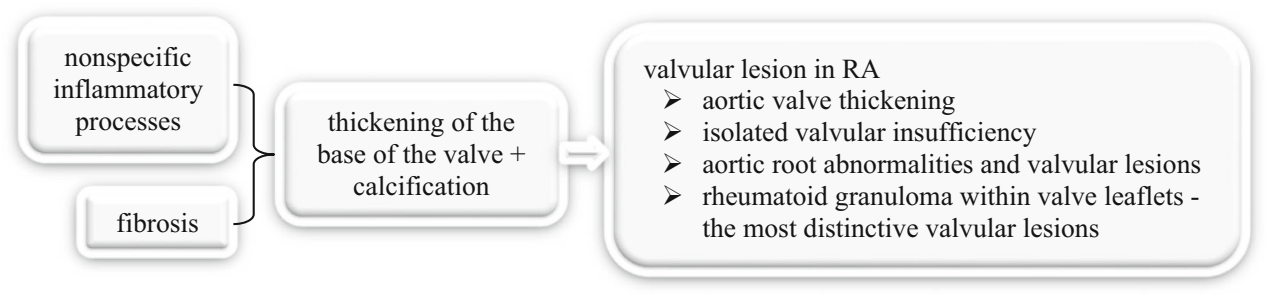


more severe when accompanied by APS and that patients with APS required surgical intervention more frequently, with a greater perioperative risk. [20]

Several treatments for SLE are available, yet there is currently no cure [21]. One study recommends regular screening via echocardiogram for patients with elevated aPL levels, as they appear to be more at risk. In this study, the use of echocardiogram is demonstrated to be an effective diagnostic tool for valvular abnormalities in SLE, as it uncovered valvular defects in $61 \%$ of SLE patients. Moreover, the authors noted that transesophageal echocardiograms are capable of generating higher resolution images of valvular damage as compared to transthoracic echocardiograms and thus are preferable in such diagnosis [19]. Transesophageal echocardiography (TEE) is recommended if degree of valve pathology is not clear on transthoracic echocardiography or for surgical planning. Additionally, aggressive anticoagulant or anti-platelet therapy is recommended by some experts, due to the presence of valvular vegetations in SLE, which may augment the development of thromboembolic complications, such as stroke [20].

A recent study has recommended the use of cardiovascular magnetic resonance (CMR) as the first line, non-invasive cardiac imaging modality, due to its ability to detect cardiovascular involvement in $43.3 \%$ of SLE patients [12•]. This low rate of false negatives associated with CMR is a result of its capability in detecting subclinical cardiac involvement, as only $20 \%$ of asymptomatic patients exhibit left ventricular abnormalities [12•]. Given the often asymptomatic nature of valve abnormalities in SLE patients, it was reported that only 4-6\% of APS diagnosed patients develop severe valvular regurgitation that requires valvular replacement surgery. However, this rate rises when renal failure is involved, as it causes more rapid valve deterioration. [17] Moreover, one retrospective analysis concluded that cardiac surgery in SLE confers a high rate of mortality and morbidity, with early and late death reported in $17 \%$ and $10 \%$ of patients, respectively. The main cause of these deaths was sepsis, with at least one postoperative complication occurring in $63 \%$ of cases. The authors thus recommend that preoperative risk scores specific to SLE be developed to help guide medical and/or surgical management. [22]

\section{Systemic Sclerosis}

Systemic sclerosis is an autoimmune disease with unknown triggers and is characterized by aberrant interstitial and
Fig. 2 Overview of aortic valve disorders in antiphospholipid antibody syndrome

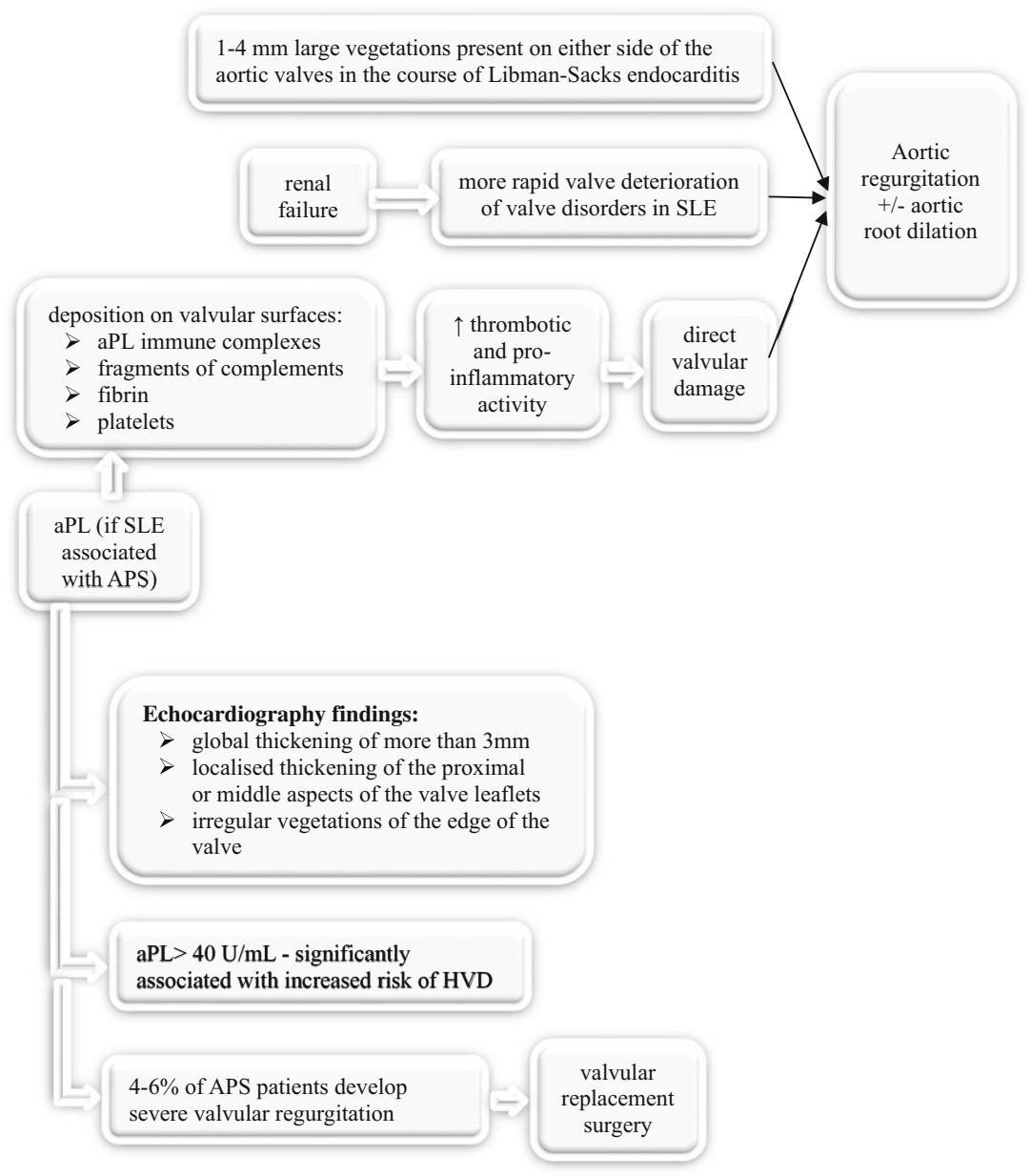


perivascular fibrosis of multiple organs: the skin, GI, kidneys, lungs, and heart muscle [23]. The heart valves are less commonly affected with mitral valve prolapse and aortic stenosis most commonly encountered in scleroderma [24]; the latter being the rarer.

Within the last 10 years, 3 cases of systemic sclerosis with aortic stenosis have been described in the literature. The first 2 cases were of women aged 59 and 73 that had worsening dyspnea due to aortic stenosis demonstrated by echocardiography. The younger patient had limited scleroderma with autoimmune liver cirrhosis complicated by esophageal varices, while the older patient had systemic sclerosis, Sjogren syndrome, mild pulmonary hypertension, antiphospholipid antibody syndrome, and multi-nodular goiter [24]. The third case was that of a 69-year-old woman that presented with severe dyspnea due to aortic stenosis diagnosed via trans-thoracic echocardiography; she had a trans-aortic gradient of $45 \mathrm{mmHg}$ and valve area of $0.9 \mathrm{~cm}^{2}$. She had limited scleroderma without lung involvement demonstrated by CT lung imaging [25]. The aortic valves of the 3 patients had 3 different histopathologic findings. Examination of the aortic valve from the first patient revealed only dense calcification, while that of the second patient revealed calcification along with fibrin and platelet deposits. The histologic examination of the third patient's aortic valve had dense, acellular fibrosis with few calcifications. Based on these findings we may assume that the pathogenesis of aortic stenosis in scleroderma could take the form of aberrant fibrosis similar to other organs in the body. As with the third patient, it could be as a result of chronic hemodynamic stress on the valve due to elevated afterload in scleroderma, and this is likely suggested by the dense calcification of the valve of the first patient, which is also responsible for aortic stenosis in senile aortic stenosis. Valvular fibrosis may also be due to comorbidities presenting with scleroderma, as the fibrin and platelet deposits in the second patient may be secondary to antiphospholipid antibody syndrome [24].

Hence, aortic stenosis in scleroderma does not have a specific pathogenesis. The three patients were managed by replacing their aortic valves with biological prostheses [24, 25] The first and second patients were asymptomatic after the surgery and were discharged after 7 days, and upon followup after 38 months and 12 months, they were both stable. No infectious complications were noted in both patients after the surgery despite being on corticosteroids. They were also placed on ACE inhibitors after the surgery because they slowed down collagen synthesis [24]. The recovery of the third patient was also uneventful and was discharged on day 6 after the operation. The patient was not on corticosteroid and did not have infectious complications. Follow-up after 1 year was positive; the patient was in sinus rhythm and in NYHA class 1 and well-functioning prosthesis with a mean transprosthetic gradient of $15 \mathrm{mmHg}$ [25].

\section{Sjogren Syndrome}

Sjogren syndrome is characterized by chronic lymphocytic infiltration of salivary glands, lacrimal glands, and other exocrine glands in the body that results in dryness, burning, and pruritus of the eyes and blurriness of vision. Patients also suffer from xerostomia and its consequences such as dysphagia, decreased taste sensation, and cracks and fissures in the mouth. SS is highly associated with autoantibodies SS-A and SS-B [23].

Although the aortic valve is rarely affected in SS, aortic stenosis with or without regurgitation has been described as the echocardiographic findings in SS with aortic valve involvement [26]. Patients present with the main complaints of exertional dyspnea, syncope, and chest pain. The aortic valves appear stiffened, calcified, and have restricted motion on echocardiography $[26,27]$.

The cases of SS with aortic involvement described in the literature are above age 60 , and the echocardiographic and gross examination findings could also be attributed to aortic valve sclerosis, which is the manifestation of atherosclerosis at the level of the aortic valve, which is associated with aging. However, histopathologic examination may help exclude aortic valve sclerosis as the primary cause of the patients' aortic valve disease as lipid-laden macrophages present in aortic valve sclerosis [28] would not be present if SS was the sole cause of the stenotic features.

If $\mathrm{SS}$ is the primary cause, nodular calcifications and hyaline degeneration with myxomatous degeneration with or without lymphocytic infiltration would be the predominant histopathologic findings. The absence of lymphocytic infiltration has been attributed to glucocorticoid use. However, in most cases, the primary cause of stenosis is not definitive because patients might have a history of rheumatic heart disease or aortic valve sclerosis in addition to SS [26]. Antiinflammatory medications such as glucocorticoids and hydroxychloroquine were associated with the improvement of symptoms as well as echocardiographic findings in a patient with SS [27].

\section{Aortic Valve Disorders in Seronegative Spondyloarthropathies}

\section{Ankylosing Spondylitis}

Ankylosing spondylitis is a disease characterized by sacroiliitis, enthesitis of the vertebral bodies (lumbar) that results in their fusion. It is more common in men with an onset in the second and third decades; lower back pain and stiffness that improve with exercise are typical complaints. About $90 \%$ of those affected are HLA-B27 positive [23]. Aortic valve diseases in ankylosing spondylitis are aortic 
insufficiencyregurgitation and rarely stenosis and regurgitation of bicuspid aortic valve [29-31]. Overall, $80 \%$ of patients with ankylosing spondylitis have aortic valve and/or aortic root involvement [32].

Aortic regurgitation can occur with aortic root dilation; for example, a 44-year-old male patient who was found to have aortic root dilation of $5 \mathrm{~cm}$ and severe regurgitation on echocardiography; the patient was managed by valve replacement. Histopathological examination of the aortic valve cusps, root, and sinuses revealed fibrous tissue deposition in the adventitia and intima. Platelet aggregation in the inflammatory site is thought to be involved in fibroblast activation. Fibrosis was also present beneath the aortic valve and is responsible for the subaortic ridge, which can be detected on echocardiography. The subaortic ridge could extend to the anterior leaflet of the mitral valve and may prevent closure of the leaflet resulting in mitral regurgitation [29]. Figure 3 summarizes aortic lesions seen in ankylosing spondylitis.

Aortic valve replacement may be a way to manage patients with ankylosing spondylitis who present with signs and symptoms of heart failure secondary to aortic regurgitation. However, autopsy findings in 5 of 8 patients who underwent aortic valve replacement still revealed root dilation and valvular abnormalities consistent with aortic regurgitation [29]. Although the nature of the valves used was not stated, such findings indicate the need for recurrent valvular replacement in those with seronegative spondyloarthropathy such as ankylosing spondylitis or psoriatic arthritis $[31,33]$. Interestingly, a study of a patient with ankylosing spondylitis revealed that immunosuppressive therapy prevented the need for aortic valve replacement in addition to slowing the progression of joint inflammation [31]. Only a single case of bicuspid aortic valve stenosis in ankylosing spondylitis has been described in the literature in the last 10 years. The patient was a 65 -year-old male with aortic dilation of $5 \mathrm{~cm}$ and stenosed bicuspid aortic valve with calcification detected via echocardiography. However, it was not stated if the bicuspid valve was congenital and developed chronic calcification as a result of stress or if the patient had a tricuspid valve that degenerated to take the form of bicuspid valve on echocardiography as a result of ankylosing spondylitis. There are no specific recommendations for ankylosing spondylitis; however, it is reasonable to follow diagnostic and treatment options used in other diseases known to cause aortic regurgitation and/or root dilation [32].

\section{Reactive Arthritis}

Reactive arthritis ( $\mathrm{ReA})$ is an immune-mediated oligoarthritis that develops secondary to a gastrointestinal or genitourinary tract infection. Urethritis and conjunctivitis are also common in those with ReA. Although the pathogenesis of ReA is not well understood, it is believed to be an interplay between the presence of bacterial antigens in the joints, the interaction between the host and bacterial antigen and the immune response against the antigens. It has also been thought that some of the bacterial antigens are molecularly similar to some selfantigens present in other body parts affected in ReA and hence this molecular mimicry results in the immune cells targeting the host tissues. ReA is strongly associated with HLA-B27 genotype; this has been partly explained by the fact that HLA-B27 shares some amino acid sequences with the bacteria that GI/GU infections [34]. However, ReA is also sometimes seen in patients that lack the HLA-B27 phenotype [35]; however, the underlying mechanism is yet to be determined.

The valvular manifestation in $\mathrm{ReA}$ is aortic regurgitation. The time from the diagnosis of ReA to development of aortic regurgitation varies among patients. On average, it is usually preceded by musculoskeletal involvement by 13 years; however, it may be detected from 4 days to 61 years after diagnosis. Patients may be asymptomatic and be detected during routine physical. ECG findings may include left ventricular hypertrophy and left axis deviation/fascicular block. Findings on echocardiogram may include trileaflet aortic valves that move as bileaflet due to commissural fusion, aortic root dilation, left ventricular dilation with hypertrophy, and left ventricular systolic dysfunction [36]. In a case that was negative
Fig. 3 Overview of aortic and aortic valve disorders in ankylosing spondylitis

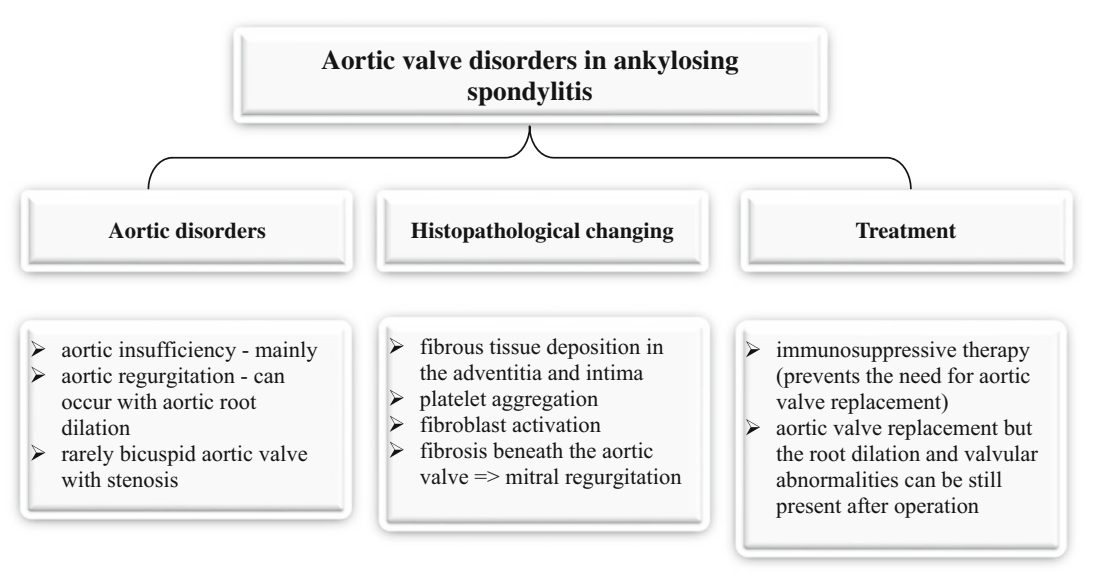


for HLA-B27, diffuse aortitis and annular ectasia were discovered during operation; valvular biopsy revealed myxomatous degeneration without inflammatory infiltrates [35]. Once detected, routine follow-up is necessary to monitor the progression and assessment for aortic valve replacement indications. Some patients may be asymptomatic; however, the extent of aortic valve deterioration between consecutive follow up in some has warranted the need for replacement despite being asymptomatic [36].

Little is known regarding the prognosis of patients with ReA after aortic valve replacement. In 2 cases, repeated echocardiography 4 and 5 years following aortic valve replacement demonstrated normal valvular function without relapse. However, a case was reported with severe calcification of a bovine bioprosthetic aortic valve after 7 years of replacement. The patient was also found to have severe coronary calcification during the procedure and required CABG. It was thought that the underlying degree of inflammation was responsible for the continued calcification [36]. Therefore, more studies are needed in which patients are followed for a longer period to determine if they suffer a relapse and to determine the factors that contribute to the severity of aortic involvement.

\section{Aortic Valve Disorders in Vasculitis}

\section{Takayasu Arteritis}

Takayasu arteritis is a vasculitis of unknown etiology that predominantly affects the aorta, the great vessels, and the pulmonary arteries [23]. There is a chronic inflammation of the arterial wall, which is transmural and characterized histologically by mononuclear cell infiltrates and fibrosis of the vessel wall that results in stenosis of the lumen in some cases and aneurysm of vessel wall in a few cases [23]. Aortic regurgitation is the valvular disorder that occurs in Takayasu arteritis $[37,38]$ and is the result of aortic root dilation. Echocardiogram shows normal valvular cusps [37]. Management is aortic valve replacement; however, aneurysm of the right sinus of Valsalva (discovered incidentally via echocardiogram during routine follow-up) developed 14 years after valve replacement in a patient despite being on daily prednisone. Histopathologic examination of the sinus revealed disrupted elastic fibers in the media, granuloma, and marked collagen deposition in the adventitial. The patient underwent aortic root replacement [38].

The 2010 AHA guidelines recommend thoracic aorta imaging with CT or MR for detection of aneurysms or luminal stenosis [32]. Imaging of the entire aorta with CT or MR angiography is recommended in suspected cases of aortic aneurysm [39].

\section{Granulomatosis with Polyangiitis}

This is a proteinase 3 anti-neutrophilic cytoplasmic antibody (PR3-ANCA) positive necrotizing vasculitis characterized by the presence of necrotizing granuloma of the upper and/or lower respiratory tract, necrotizing or granulomatous vasculitis of small- and medium-sized vessels in lungs, upper airways, and other organs and crescentic glomerulonephritis [40]. Although valvular involvement in the disease is quite rare, aortic regurgitation and aortic stenosis have been reported in patients with granulomatosis with polyangiitis (GPA) with aortic regurgitation being more prevalent [41, 42].

The onset of aortic regurgitation in GPA is variable because in some cases, it was present at the time of diagnosis, and in other cases, it presented a few years after diagnosis. More so, the immunosuppressive therapy used in GPA seems to have no impact on the development of aortic regurgitation because some patients may develop symptoms of aortic regurgitation despite being on immunosuppressive therapy to control the disease progression [41]. Both chronic and acute manifestations could be present (e.g., the perforation of the cusps of the aortic valve) [42]. Aortic regurgitation may be the only sign of relapse in GPA patients that were in remission due to immunosuppressive therapy. Furthermore, the onset of aortic valve regurgitation correlates with elevated PR3-ANCA [43].

Macroscopically, affected aortic valves have thickened cusps. On histopathologic examination, dominant findings are granulomatous inflammation with polymorphonuclear micro-abscesses and foci of necrosis [44]. These findings are located in the central layer of the valve. Echocardiography, blood and valve cultures, and serology should be done in patients with GPA with valvular involvement to rule out infectious endocarditis. The absence of vegetations, negative blood and valve cultures, and serology and the absence of microbes on histopathologic examination were documented in one study of patients with aortic regurgitation secondary to GPA [45].

Cases of aortic regurgitation in GPA have been managed with either increasing the dose of immunosuppressive therapy or aortic valve replacement. Increasing the dose of cyclophosphamide did slow down the progression of aortic regurgitation in a few cases. However, increasing the dose of rituximab did not improve the findings in a few patients with valvular granulomas detected via transesophageal echocardiography. Rather aortic valve replacement was performed on these patients [46] The differences in the potency of cyclophosphamide and rituximab or severity of valve involvement may be the reason why not all cases respond to an increased dose of immunosuppressive therapy. Perhaps more studies need to be carried out on the most effective immunosuppressive therapy for those with GPA and aortic regurgitation. Follow-up studies need to be done on these patients to determine the effectiveness of valve replacement, i.e., if the disease recurs or not due 
chronicity of GPA. Without randomized studies, it is difficult to broadly apply these reports of outcomes from medical treatment or surgical valve replacement to patient care.

\section{Churg-Strauss Syndrome}

Churg-Strauss syndrome (CSS) is a systemic necrotizing granulomatous vasculitis of small to medium muscular arteries and microvessels and is associated with asthma, allergic rhinitis, peripheral eosinophilia, and lung infiltrates. Myeloperoxidase antineutrophil cytoplasmic antibody (MPO-ANCA) is present in less than $50 \%$ of cases [23]. The aortic valve pathology associated with CSS is aortic regurgitation [47, 48]. Histopathologic examination reveals valve leaflets infiltrated by eosinophils, lymphocytes and plasma cells; necrotizing granulomas are also seen. Grossly, the valve is dense and thick due to fibrosis and inflammatory reaction [48]. Anti-inflammatory medications like prednisolone and cyclophosphamide resulted in clinical improvement in a patient with aortic regurgitation secondary to CSS. However, the patient later required aortic valve replacement due to relapse [47]. Further studies are needed to understand the role of medical therapy on the impact of development and/or progression of valve disease associated with CSS.

\section{Behçet's Disease}

Behçet's disease is a chronic vasculitis involving multiple organs and is diagnosed based on the presence of recurrent oral aphthous ulcers and at least 2 of skin manifestations, genital ulcerations, eye lesions, and a positive pathergy test [49]. It is associated with HLA-B51 [50]. About 25\% of patients with Behçet's disease have valvular involvement, and aortic regurgitation is the most common valvular pathology [51, 52]. The echocardiographic findings are aneurysm, elongation and prolapse of aortic cusps, echocardiographic free space, and vegetation like lesions $[53,54]$. These findings are not unique to Behçet's disease, however, and may be seen in different forms of endocarditis, which have to be excluded.

Although the exact pathology and molecular basis of aortic valve regurgitation in Behcet disease is unknown, regurgitation may be secondary to aneurysm of the ascending aorta due to vasculitis [51, 52]; the cusps of the valves maybe normal or fibrosed. Grossly visible changes include annulus dilatation, sinus of Valsalva aneurysm, cusp fenestration, and fusion. Histopathologic evaluation of the valve and ascending aorta may reveal lymphoplasmacytic infiltrates, neutrophils, histiocytes, eosinophils and occasional giant cells, myxoid degeneration, focal necrosis, and fibrotic thickening [52, 54].

Some patients will meet indications for aortic valve replacement due to severe aortic valve regurgitation, and some may need concomitant aortic root or ascending aortic replacement. The role of immunosuppressive therapy to prevent valve degeneration is the focus of ongoing research [55]. There are no specific recommendations for Behcet disease; however, it is reasonable to follow diagnostic and treatment options used in other diseases known to cause aortic regurgitation. Special focus should be on immunosuppressant therapy, which helps lessen the inflammatory state.

\section{Aortic Valve Disorders in Heritable Connective Tissue Diseases}

\section{Marfan's Syndrome}

Marfan's syndrome (MFS) is an autosomal dominant connective tissue disorder with cardiovascular involvement [56, 57]. With a prevalence of around 1/3000 to $1 / 5000$ individuals, the cause of the disorder has been extensively linked to mutations in the pleiotropic FBN-1 gene, which encodes an extracellular matrix protein (ECM), fibrillin-1 [58]. Fibrillin-1 is critical for microfibril formation and organizing ECM components, as well as sequestering transforming growth factor (TGF)- $\beta$, thus regulating its bioavailability [59]. The induction of TGF- $\beta$ signaling, through increased angiotensin II receptor signaling as a result of fibrillin-1 underproduction, is associated with an increase in apoptosis and subsequent loss of smooth muscle nuclei [57]. Moreover, antagonism of TGF- $\beta$ by antibodies has exhibited some improvement with regard to the pulmonary manifestations of the disease [60]. Thus, the increased activity of TGF- $\beta$ observed in MFS is believed to play a pivotal role in the adverse clinical manifestations of the disorder, which include microtubule deformations, cystic medial necrosis (CMN), and overall connective tissue weakness [61]. Figure 4 summarizes the mechanisms leading to aortic lesions seen in Marfan's syndrome.

MFS demonstrates clinical variability, as phenotypes range from very mild to severe, even among family members with FBN-1 gene mutations [62]. It is suggested that deletions in various regions of the gene often result in different clinical phenotypes [58]. Franken et al. demonstrated that patients with a haploinsufficiency (HI) mutation in the FBN1 gene were found to have more rapid dilation rates of the aortic root and ascending aorta, in contrast to dominant negative (DN) form of the mutation. About $79 \%$ of patients with cardiovascular events were HI-FBN1 mutants, whereas only $48 \%$ of patients without these events belonged to this mutant type. This demonstrates that patients possessing the HI-FBN1 mutation are at a greater risk for the combined clinical endpoint, compared to those with the $D N-F B N 1$ mutation, a finding consistent even at younger ages [63].

Cardiovascular abnormalities, such as dissecting thoracic aortic aneurysms (TAA) and progressing aortic root enlargement, are major causes of morbidity and mortality seen in MFS. These cardiovascular deficits may present either in 
Fig. 4 Overview of aortic valve disorder in Marfan's syndrome

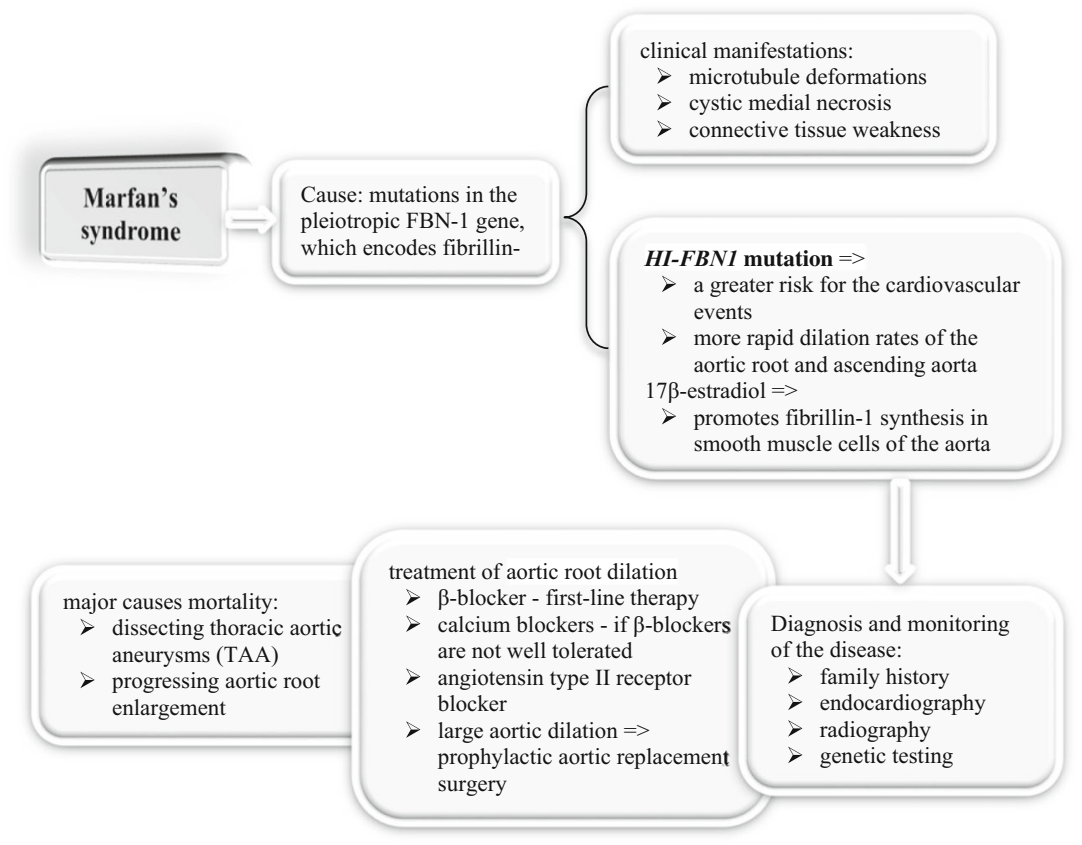

neonatal life, where they are often fatal, or in adolescence, and worsen with age [64] Furthermore, the impact of gender and pregnancy on the cardiovascular implications of MFS has been increasingly studied [65].

One study found that men below the age of 30 were at a greater risk than women for aortic dilation and aortic events [66], while another study discovered an increased incidence for aortic surgery at baseline in men (38\%), compared to women (19.4\%) [67]. The mechanism to explain the influence of gender on cardiovascular disease in MFS was subsequently investigated by Renard et al. who showed that $17 \beta$-estradiol promoted fibrillin-1 synthesis in smooth muscle cells of the human aorta [65]. Due to improved medical and surgical therapies for aortic dilation, the life expectancy of those suffering from MFS has increased from 47 to 75 years. Echocardiography should be performed at the time of diagnosis. Definitive diagnosis as well as surveillance imaging is accomplished with $\mathrm{CT}$ or magnetic resonance imaging of the entire aorta $[32,39]$. CT angiography or magnetic resonance angiography (CTA or MRA) of the entire aorta is needed for diagnostic imaging [39]. Furthermore, genetic testing has evolved into an essential diagnostic tool of the disease, owing to its $97 \%$ effectiveness in its ability to detect FBN1 mutations. Cumulatively, genetic testing, radiography, and family history are currently utilized in diagnosing MFS [68]. For patients with familial thoracic aortic aneurysms, screening of first degree relatives (every 5 years) is prudent to prevent premature death $[32,39]$.

MFS patients with severe progression of the disease, resulting in aortic dilation, may undergo prophylactic aortic replacement surgery, which replaces the diseased aorta with a Dacron graft. Surgical intervention is recommended when aortic aneurysm reaches 4.5 to $5.0 \mathrm{~cm}$ in diameter [39, 69]. Additionally, current guidelines recommend endocardiography for children and those with accelerated aortic root growth twice a year. In order to manage the cardiovascular manifestations of the disease, $\beta$-blocker medication is generally used as the first-line of therapy, while calcium blockers are prescribed to those patients who cannot tolerate $\beta$-blockers [64]. However, several other potential therapeutic drugs are currently being investigated, including angiotensin type II receptor blockade, which minimizes TGF- $\beta$ activity. Initial results are promising, with one study citing no difference between $\beta$-blocker use and angiotensin type II receptor blockade on aortic root dilation [70]. According to the 2010 AHA and 2014 ESC guidelines, prophylactic use of betablockers, angiotensin II receptor blockers, and angiotensin converting enzyme inhibitors is recommended to control blood pressure. This slows the progression of aortic dilation as well improves survival in this population $[32,39]$.

\section{Ehlers-Danlos Syndrome}

Manifestations of EDS stem from the genetic defect in the synthesis and processing of collagen, which affects the tensile strength and integrity of connective tissues [23]. Based on clinical features, there are six types of EDS, which are the classic (with skin involvement such as easy bruising and atrophic scars and hypermobility of joints), hypermobility (hypermobility, pain and dislocation of joints), vascular (involving arterial and hollow organ rupture, thin skin that bruises easily, and hyperextensibility of small joints), kyphoscoliosis (congenital scoliosis, hypotonia, joint hypermobility, and ocular fragility), arthrochalasia (severe laxity of joint, mild skin 
involvement with bruising, and scoliosis), and dermatosparaxis EDS (comprising of severe skin involvement with cutis laxa and bruising) [71].

Aortic regurgitation is the aortic valve disorder present in EDS and has been associated with the classic, vascular, kyphoscoliosis, and arthrochalasia EDS [72-74]. Apart from mild asymptomatic aortic regurgitation, which is discovered during echocardiography for symptomatic mitral valve regurgitation in patients with EDS, patients present with exertional dyspnea, orthopnea, and palpitations [74].

Aortic regurgitation in EDS mostly appears to be secondary to aortic root dilation [72, 74, 75]. Patients with mild aortic regurgitation are monitored regularly because aortic regurgitation in EDS is often progressive [73]. Patients with symptomatic severe aortic regurgitation are offered surgical replacement [75]. The guidelines recommend surgical intervention when aortic size is $4-5 \mathrm{~cm}$ in diameter [32]. ESC guidelines have no set cutoffs, however, recommend lower threshold than $5.5 \mathrm{~cm}$ for surgical intervention [39].

Type 4 EDS (also known as vascular EDS) occurs due to mutations in type 3 collagen (COL3A1 gene). It is strongly associated with increased aortic friability and fragility leading to vascular complications such as aortic dissections and rupture, at a very young age [76]. Consequently, noninvasive screening modalities (CTA or MRA) are preferred over invasive angiography in this population $[32,77]$. Surgical intervention is recommended at aortic diameter $4.4 \mathrm{~cm}$ [77]. In addition, the guidelines recommend excision of the sinuses in combination with a modified David reimplantation operation in these patients with dilatation of the aortic root and sinuses of Valsalva where possible [32].

\section{Loeys-Dietz Syndrome}

Loeys-Dietz syndrome (LDS) is a autosomal-dominant disorder that occurs as a result of loss-of-function mutations of genes involved in the TGF- $\beta$ signaling pathway that ultimately lead to increased TGF- $\beta$ signaling [72]. It is characterized by craniofacial abnormalities, arterial tortuosity, and aortic root aneurysm $[72,78]$. Thoracic aortic aneurysms (TAA) in LDS are prevalent at narrower aortic diameters, including medium-sized arteries [79]. In addition to arising at a smaller diameter, these aortic ruptures often occur at an earlier age, making LDS clinically distinct from MFS, with a mean life expectancy of 26 years [78]. Moreover, for patients with LDS, pregnancy is considered a high risk, with a wide range of complications being reported both during gestation and postpartum period $[61,78]$.

Patients with LDS are classified into 5 subtypes, based on the presence of specific mutated genes: LDS1 (TGFBR1), LDS2 (TGFBR2), LDS3 (SMAD3), LDS4 (TGFB2), and LDS5 (TGFB3). Twenty TGFBR1 and TGFBR 2 are transmembrane proteins, which play a role in increased TGF- $\beta$ signaling [61]. TGF- $\beta$ is critical for the development and maintenance blood vessels among other functions. When overexpressed, it is thought to induce collagen and elastin abnormalities that lead to the clinical manifestations of LDS $[61,80]$. Studies comparing phenotypic differences between TGFBR1 and TGFBR2 mutations have shown that aortic dissection occurs only at large diameters with TGFBR1 mutations. In addition, gender differences exist between both types: TGFBR1 mutation affected men earlier with more frequent involvement of the aorta [81].

The management of LDS involves the use of $\beta$-blockers as the first line of therapy, with or without the use of losartan, an angiotensin type II receptor blocker [80]. Due to the aggressive nature of vascular disease, however, surgical intervention of the aortic root is considered earlier as compared to MFS, potentially at any diameter above 40 $45 \mathrm{~mm}[69,82]$. Many studies have cited aortic dissections taking place at diameters less than $50 \mathrm{~mm}$ [78]. Moreover, the high risk of aortic rupture has often necessitated aortic root replacement with prosthetic graft in LDS patients at 16.9 years. Nonetheless, recommendations for prophylactic surgery should be made on an individual basis [80]. Risks associated with the prostheses have led to the development of valve-sparing aortic root replacement (VSRR). VSRR eliminates the need for long-term anticoagulation therapy and subsequent surgeries to replace worn out prosthetic valves [83]. Recent studies on short- and mid-term outcomes of VSRR have shown superiority over traditional valve replacements in terms of survival and need for reoperation [84]. Unfortunately, there is significantly increased likelihood of pseudoaneurysms in young children following VSRR; thus, further long-term studies are needed to define the optimal surgical management strategy. In addition, ongoing surveillance imaging with CTA or MRA is warranted post operatively as well [83].

\section{Conclusions/Perspective for Future Work}

Further studies are needed to identify key cytokines and inflammatory mediators that contribute to aortic valve damage in connective tissue disorders, which may be specifically selected for targeting in appropriate immunotherapies. This will help guide choice of therapy with anti-inflammatory agents in order to slow the progression of aortic valve damage as well as prevent the need for valve replacement. Moreover, given that many of the diseases vary in their prevalence with regard to sex, further studies are needed to investigate pathomechanisms, which may contribute to the discrepancies associated with gender. 


\section{Compliance with Ethical Standards}

Conflict of Interest Bogna Grygiel-Górniak, Mary-Tiffany Oduah, Abdulbaril Olagunju, and Michal Klokner declare that they have no conflict of interest.

Human and Animal Rights and Informed Consent This article does not contain any studies with human or animal subjects performed by any of the authors.

Open Access This article is licensed under a Creative Commons Attribution 4.0 International License, which permits use, sharing, adaptation, distribution and reproduction in any medium or format, as long as you give appropriate credit to the original author(s) and the source, provide a link to the Creative Commons licence, and indicate if changes were made. The images or other third party material in this article are included in the article's Creative Commons licence, unless indicated otherwise in a credit line to the material. If material is not included in the article's Creative Commons licence and your intended use is not permitted by statutory regulation or exceeds the permitted use, you will need to obtain permission directly from the copyright holder. To view a copy of this licence, visit http://creativecommons.org/licenses/by/4.0/.

\section{References}

Papers of particular interest, published recently, have been highlighted as:

- Of importance

•- Of major importance

1.• van Zanten V, Jet JCS, et al. Comparison of the effects of exercise and anti-TNF treatment on cardiovascular health in rheumatoid arthritis: results from two controlled trials. Rheumatol Int. 2018. https://doi.org/10.1007/s00296-018-4183-1 Springer Nature America, Inc https://www.ncbi.nlm.nih.gov/pubmed/30421104 In patients with rheumatoid arthritis, exercise induced a reduction in overall CVD risk and improvement in vascular function, a finding not observed with anti-TNF treatment.

2. Hunter TM, et al. Prevalence of rheumatoid arthritis in the United States adult population in healthcare claims databases, 2004-2014. Rheumatol Int. 2017;37(9):1551-7. Springer Nature. https://doi. org/10.1007/s00296-017-3726-1.

3. Kumar KV, Hari S, et al. Prevalence of left ventricular dysfunction in rheumatoid arthritis. J Family Med Primary Care. 2017;6(3): 622. https://doi.org/10.4103/2249-4863.214431 Medknow, https://www.ncbi.nlm.nih.gov/pubmed/29417020.

4. Meune C, Touze E, Trinquart L, Allanore Y. Trends in cardiovascular mortality in patients with rheumatoid arthritis over 50 years: a systematic review and meta-analysis of cohort studies. Rheumatology. 2009;48:1309-13.

5. Choy E, et al. Cardiovascular risk in rheumatoid arthritis: recent advances in the understanding of the pivotal role of inflammation, risk predictors and the impact of treatment. Rheumatology. 2014;53(12):2143-54. https://doi.org/10.1093/rheumatology/ keu224 Oxford University Press (OUP), https://www.ncbi.nlm. nih.gov/pmc/articles/PMC4241890/\#keu224-B9.

6. Corrao S, et al. Heart involvement in rheumatoid arthritis: systematic review and meta-analysis. Int J Cardiol. 2013;167(5):2031-8 Elsevier BV, doi:10.1016/j.ijcard.2012.05.057.https://www.ncbi. nlm.nih.gov/pubmed/22703938.
7. Asopa $\mathrm{S}$, et al. Early prosthetic valve failure in a patient with rheumatoid arthritis. J Card Surg. 2009;24(1):85-7. https://doi.org/10. 1111/j.1540-8191.2008.00723.x Wiley, https://www.ncbi.nlm.nih. gov/pubmed/18793234.

8. Beckhauser AP, Vallin L, Burkievcz CJ, Perreto S, Silva MB, Skare TL. Valvular involvement in patients with rheumatoid arthritis. Acta Reumatol Port. 2009;34(1):52-6. https://www.ncbi.nlm.nih. gov/pubmed/19449476.

9. Hunter TM, et al. Prevalence of rheumatoid arthritis in the United States adult population in healthcare claims databases, 2004-2014. Rheumatol Int. 2017;37(9):1551-7. Springer Nature. https://doi. org/10.1007/s00296-017-3726-1.

10. Del Buono M, et al. Interplay of inflammation, oxidative stress and cardiovascular disease in rheumatoid arthritis. Heart. 2018. https:// doi.org/10.1136/heartjnl-2018-313313 pp. heartjnl-2018-313313. $B M J$, https://www.ncbi.nlm.nih.gov/pubmed/30072365 Increased cardiovascular disease risk in males and postmenopausal females is the result of maladaptive cytokine and immune signaling (as these markers correlate directly with severity of subsequent CAD) and not solely the effect of traditional CVD risk factors.

11. Vizzardi E, et al. Evaluation of ascending aorta wall in rheumatoid arthritis by tissue and strain Doppler imaging during anti-tumor necrosis factor-A therapy. Clin Cardiol. 2014;37(12):738-43. https://doi.org/10.1002/clc.22332 Wiley, https:/www.ncbi.nlm.nih. gov/pubmed/25236839.

12. Burkard T, et al. The heart in systemic lupus erythematosus - a comprehensive approach by cardiovascular magnetic resonance tomography. PLoS One. 2018;13(10):e0202105. https://doi.org/10. 1371/journal.pone.0202105 Public Library Of Science (Plos), https://www.ncbi.nlm.nih.gov/pmc/articles/PMC6167090/ Cardiac magnetic resonance imaging plays a crucial role in the detection of subclinical/asymptomatic cardiac complications of SLE allowing for earlier therapy.

13. Li H, et al. Risk of coronary artery disease in patients with systemic lupus erythematosus: a systematic review and meta-analysis. Am J Med Sci. 2018;356(5):451-63. https://doi.org/10.1016/j.amjms. 2018.08.001 Elsevier BV, https://www.clinicalkey.com/\#!/content/ playContent/1-s2.0-S0002962918302982?returnurl=https:\%2F\% 2 Flinkinghub.elsevier.com $\% 2$ Fretrieve\% 2 Fpii\% 2FS0002962918302982\%3Fshowall\%3Dtrue\&referrer=https:\% $2 \mathrm{~F} \% 2 \mathrm{Fwww}$.ncbi.nlm.nih.gov\%2F\&scrollTo $=\% 23$ references.

14. Kansara B, et al. Aortic valve replacement in a patient with systemic lupus eerythematosus. J Anaesthesiol Clin Pharmacol. 2013;29(2): 248. https://doi.org/10.4103/0970-9185.111656 Medknow, https:// www.ncbi.nlm.nih.gov/pmc/articles/PMC3713678/.

15. Pons-Estel GJ, et al. Understanding the epidemiology and progression of systemic lupus erythematosus. Semin Arthritis Rheum. 2010;39(4):257-68. Elsevier BV. https://doi.org/10.1016/j. semarthrit.2008.10.007.

16. Tsanaktsi A, et al. Th1/17 cells, a subset of Th17 cells, are expanded in patients with active systemic lupus erythematosus. Clin Immunol. 2018;195:101-6. https://doi.org/10.1016/j.clim.2018.08. 005 Elsevier BV, https://www.sciencedirect.com/science/article/pii/ S1521661618300214?via\%3Dihub.

17. Watad A, et al. The association between systemic lupus erythematosus and valvular heart disease: an extensive data analysis. Eur $J$ Clin Investig. 2017;47(5):366-71. https://doi.org/10.1111/eci. 12744 Wiley, https://onlinelibrary.wiley.com/doi/full/10.1111/eci. 12744.

18. Bourré-Tessier J, et al. Features associated with cardiac abnormalities in systemic lupus erythematosus. Lupus. 2011;20(14):1518 25. https://doi.org/10.1177/0961203311420318 SAGE Publications, https://journals.sagepub.com/doi/abs/10.1177/ 0961203311420318?rfr dat=cr pub\%3Dpubmed\&url ver=Z39. 88-2003\&rfr_id=ori\%3Arid\%3Acrossref.org\&journalCode=lupa. 
19. Ruiz D, et al. Antiphospholipid antibodies and heart valve disease in systemic lupus erythematosus. Am J Med Sci. 2018;355(3):2938. https://doi.org/10.1016/j.amjms.2017.07.007 Elsevier BV, https:// www.clinicalkey.com/\#!/content/playContent/1-s2.0S0002962917304068? returnurl=https:\%2F\%2Flinkinghub. elsevier.com\%2Fretrieve\%2Fpii\%2FS0002962917304068\% 3Fshowall\%3Dtrue\&referrer=https:\%2F\%2Fwww.ncbi.nlm.nih. gov $\% 2 \mathrm{~F}$.

20. Unic $\mathrm{D}$, et al. Isolated tricuspid valve Libman-Sacks endocarditis in systemic lupus erythematosus with secondary antiphospholipid syndrome. Tex Heart Inst J. 2017;44(2):147-9. https://doi.org/10. 14503/thij-16-5856 Texas Heart Institute Journal, https://www. ncbi.nlm.nih.gov/pmc/articles/PMC5408632/.

21. Tarvin SE, O'Neil KM. Systemic lupus erythematosus, Sjögren syndrome, and mixed connective tissue disease in children and adolescents. Pediatr Clin N Am. 2018;65(4):711-37. https://doi. org/10.1016/j.pcl.2018.04.001 Elsevier BV, https://www. clinicalkey.com/\#!/content/playContent/1-s 2.0 S0031395518300403 ?returnurl=https:\%2F\%2Flinkinghub. elsevier.com\%2Fretrieve\%2Fpii\%2FS0031395518300403\% 3Fshowall\%3Dtrue\&referrer=https:\%2F\%2Fwww.ncbi.nlm.nih. gov\% $2 \mathrm{~F}$.

22. Tejeda-Maldonado J, et al. Cirugía Cardiaca En Pacientes Con Lupus Eritematoso Sistémico: Características Clínicas Y Desenlaces. Reumatol Clín. 2018;14(5):269-77. https://doi.org/ 10.1016/j.reuma.2017.01.012 Elsevier BV, https://www-ncbi-nlmnih-gov.myaccess.library.utoronto.ca/pubmed/28291723.

23. Robbins S, Aster J, Perkins J, Cotran R, Kumar V, Abbas A. Robbins and Cotran pathologic basis of disease. 9th ed. Philadelphia: Elsevier/Saunders; 2015. p. 144. 228, 505, 1213

24. Sponga S, Basso C, Ruffatti A, Gerosa G. Systemic sclerosis and aortic valve stenosis: therapeutic implications in two cases of aortic valve replacement. J Cardiovasc Med, [online] 2009;10(7), pp.560562. Available at: https://www.deepdyve.com/lp/wolters-kluwerhealth/systemic-sclerosis-and-aortic-valve-stenosis-colontherapeutic-4Z9WVTR2cR? articleList=\%2Fsearch\%3Fquery\% 3DAortic\%2Bvalve\%2Breplacement\%2Bin\%2Bsystemic\% 2Bsclerosis\%26numPerPage\%3D50 [Accessed 31 Oct. 2018].

25. Ferrari G, Pratali S, Pucci A, Bortolotti U. Aortic valve replacement in systemic sclerosis. J Cardiovasc Med, [online] 2015;16, pp.S60S61. Available at: https://www.deepdyve.com/lp/wolters-kluwerhealth/aortic-valve-replacement-in-systemic-sclerosis$3 \mathrm{uc} 6 \mathrm{dv} 1 \mathrm{Hzw}$ ?articleList=\%2Fsearch\%3Fquery\%3DAortic\% 2Bvalve $\% 2$ Breplacement $\% 2$ Bin $\% 2$ Bsystemic $\% 2$ Bsclerosis $\%$ 26numPerPage\%3D50 [Accessed 31 Oct. 2018].

26. Kono M, Aoyagi S, Okazaki T, Tayama K. Aortic stenosis in a patient with Sjogren's syndrome. Int Heart J. 2016;57(2):251-3 Available at: http://www.jstage.jst.go.jp/article/ihj/57/2/57_15349/ pdf/-char/en [Accessed 8 Feb. 2019].

27. Wang L, Wei Y, Zhang Z. A Sjögren's syndrome patient with prominent aortic valve involvement: a case report. J Peking Univ [online] 2017;49(6), p.1087. Available at: http://xuebao.bjmu.edu.cn/EN/ Y2017/V49/I6/1087 [Accessed 5 Feb. 2019].

28. Izquierdo-Gómez M, Hernández-Betancor I, García-Niebla J, MaríLópez B, Laynez-Cerdeña I, Lacalzada-Almeida J. Valve calcification in aortic stenosis: etiology and diagnostic imaging techniques. BioMed Res Int, [online] 2017; 2017, pp.1-12. Available at: http:// www.ncbi.nlm.nih.gov/pmc/articles/PMC5546080/ [Accessed 5 Feb. 2019].

29. Yuan S. Cardiovascular involvement of ankylosing spondylitis: report of three cases. Vascular, [online] 2009;17(6), pp.342-354. Available at: https://www.deepdyve.com/lp/sage/cardiovascularinvolvement-of-ankylosing-spondylitis-report-of-threeovXG3mJvXp? [Accessed 31 Oct. 2018].

30. Hwang H, Kim J, Lee S, Park C, Sohn I. Full-blown cardiac manifestations in ankylosing spondylitis. Echocardiography, [online]
2016;33(11), pp.1785-1787. Available at: https://www.deepdyve. com/lp/wiley/full-blown-cardiac-manifestations-in-ankylosingspondylitis-MhcxAaCteP? [Accessed 31 Oct. 2018].

31. Luckie M, Irion L, Khattar R. Severe mitral and aortic regurgitation in association with ankylosing spondylitis. Echocardiography, [online] 2009; 26(6), pp.705-710. Available at: https://www.deepdyve. $\mathrm{com} / \mathrm{lp} /$ wiley/severe-mitral-and-aortic-regurgitation-in-associationwith-ankylosing-EK9EEYF0Vq? [Accessed 31 Oct. 2018].

32. 2010 ACCF/AHA/AATS/ACR/ASA/SCA/SCAI/SIR/STS/SVM Guidelines for the diagnosis and management of patients with thoracic aortic disease. WRITING GROUP MEMBERS. LF Hiratzka, Bakris GL, JA Beckman, RM Bersin, VF Carr ,DE Casey, KA Eagle, LK Hermann, EM Isselbacher, EA. Kazerooni, NT Kouchoukos ,BW Lytle, DM Milewicz, DL Reich, S Sen, JA Shinn, LG Svensson, and DM Williams.

33. Muna W. Psoriatic arthritis and aortic regurgitation. JAMA: The Journal of the American Medical Association, [online] 1980;244(4), p.363. Available at: https://jamanetwork.com/ journals/jama/article-abstract/370893 [Accessed 20 Jul. 2019].

34. Colmegna I, Cuchacovich R, Espinoza L. HLA-B27-associated reactive arthritis: pathogenetic and clinical considerations. Clin Microbiol Rev. 2004;17(2):348-69 Available at: https://cmr.asm. org/content/17/2/348 [Accessed 20 Jul. 2019].

35. Misukiewicz P, Carlson R, Rowan L, Levitt N, Rudnick C, Desai T. Acute aortic insufficiency in a patient with presumed Reiter's syndrome. Ann Rheum Dis. 1992;51(5):686-7 Available at: https://ard. bmj.com/content/annrheumdis/51/5/686.full.pdf [Accessed $20 \mathrm{Jul}$. 2019].

36. Brown L, Forfia P, Flynn J. Aortic insufficiency in a patient with reactive arthritis: case report and review of the literature. HSS J. 2011;7(2):187-9 Available at: https://www.ncbi.nlm.nih.gov/pmc/ articles/PMC3145855/ [Accessed 20 Jul. 2019].

37. Ravelli A, Pedroni E, Perrone S, Tramarin R, Martini A, Burgio G. Aortic valve regurgitation as the presenting sign of Takayasu arteritis. Eur J Pediatr. 1999;158(4):281-3 Available at: http://www. deepdyve.com/lp/springer-journals/aortic-valve-regurgitation-asthe-presenting-sign-of-takayasu-XgfDttr0wh?articleList $=\%$ 2Fsearch\%3Fquery\%3Daortic\%2Bvalve\%2Bdisease $\% 2 \mathrm{Bin} \%$ 2Btakayasu\%2Barteritis [Accessed 27 Jan. 2019].

38. Yoshikai M, Ohnishi H, Fumoto H, Furutachi A. Aneurysm of the right sinus of Valsalva after aortic valve replacement in Takayasu arteritis. J Card Surg. 2007;22(2):162-4 Available at: http://www. deepdyve.com/lp/wiley/aneurysm-of-the-right-sinus-of-valsalvaafter-aortic-valve-replacement-1 A4MLwFVj5? articleList $=\%$ 2Fsearch\%3Fquery\%3Daortic\%2Bvalve\%2Bdisease $\% 2$ Bin $\%$ 2Btakayasu\%2Barteritis [Accessed 27 Jan. 2019].

39. The task force for the diagnosis and treatment of aortic diseases of the European Society of Cardiology (ESC), European Heart Journal, Volume 35, Issue 41, 1 November 2014, Pages 28732926, https://doi.org/10.1093/eurheartj/ehu281

40. Ruisi M, Ruisi P, Finkielstein D. Cardiac manifestations of Wegener's granulomatosis: case report and review of the literature. J Cardiol Cases. 2010;2(2):e99-e102 Available at: http://www. sciencedirect.com/science/article/pii/S1878540910000319 [Accessed 21 Nov. 2018].

41. Lacoste C, Mansencal N, M'rad M, Goulon-Goeau C, Cohen P, Guillevin L,0 Hanslik T. Valvular involvement in ANCAassociated systemic vasculitis: a case report and literature review. BMC Musculoskeletal Disorders, [online] 2011;12(1). Available at: http://www.ncbi.nlm.nih.gov/pmc/articles/PMC3050781/ [Accessed 21 Nov. 2018].

42. Castellanos D, Travelli F, Reyhan I, Votava-Smith J, Ramanathan A, Bar-Cohen Y. Acute aortic and mitral valve perforations caused by granulomatosis with polyangiitis. Circulation. 2015;131(24): 527-9 Available at: http://www.ahajournals.org/doi/full/10.1161/ CIRCULATIONAHA.114.014304 [Accessed 21 Nov. 2018]. 
43. Hirai K, Miura N, Yoshino M, Miyamoto K, Nobata H, Nagai T, et al. Two cases of proteinase 3-anti-neutrophil cytoplasmic antibody (PR3-ANCA)-related nephritis in infectious endocarditis. Intern Med. 2016;55(23):3485-9 Available at: http://www.ncbi. nlm.nih.gov/pmc/articles/PMC5216148/ [Accessed 21 Nov. 2018].

44. Al-Kindi S, Alaiti M, Yang M, Josephson R. Granulomatosis with polyangiitis presenting with acute aortic and mitral regurgitation: case report and big-data analysis. J Heart Valve Dis. 2017;26(1): 103-6 Available at: http://www.researchgate.net/publication/ 317084858 Granulomatosis with Polyangiitis Presenting with Acute_Aortic_and_Mitral_Regurgitation_Case_Report_and_BigData_Analysis/citations [Accessed 21 Nov. 2018].

45. Mortazavi M, Nasri H. Granulomatosis with polyangiitis (Wegener's) presenting as the right ventricular masses: a case report and review of the literature. J Nephropathol. 2012;1(1):49-56 Available at: http://www.ncbi.nlm.nih.gov/pmc/articles/ PMC3886160/ [Accessed 21 Nov. 2018].

46. Lacoste, C., Mansencal, N., M'rad, M., Goulon-Goeau, C., Cohen, P., Guillevin, L. and Hanslik, T. (2011). Valvular involvement in ANCA-associated systemic vasculitis: a case report and literature review. BMC Musculoskeletal Disorders, [online] 12(1). Available at: https://www.ncbi.nlm.nih.gov/pmc/articles/PMC3050781/ [Accessed 20 Jul. 2019].

47. Doherty L, Kumar P, Bexton R, Plummer C, Dark J, Black F, et al. Aortic regurgitation and Churg-Strauss syndrome. QJM. 2005;98(10):772-3 Available at: http://academic.oup.com/qjmed/ article/98/10/772/1602571 [Accessed 5 Feb. 2019].

48. Segal, O., Gibbs, J. and Sheppard, M. (2001). Eosinophilic aortitis and valvitis requiring aortic valve replacement. Heart, [online] 86(3). Available at: http://heart.bmj.com/content/86/3/245 [Accessed 5 Feb. 2019].

49. Rokutanda, R., Kishimoto, M. and Okada, M. (2014). Update on the diagnosis and management of Beh\&ccedil;et\&rsquo;s disease. Open Access Rheumatology: Research and Reviews, [online] p.1. Available at: https://www.ncbi.nlm.nih.gov/pmc/articles/ PMC5045120/ [Accessed 20 Jul. 2019].

50. Wallace G. HLA-B*51 the primary risk in Behcet disease. Proc Natl Acad Sci. 2014;111(24):8706-7 Available at: https://www. ncbi.nlm.nih.gov/pmc/articles/PMC4066492/ [Accessed 20 Jul. 2019].

51. Lee C, Lee J, Lee W, Lee C, Suh C, Song C, et al. Aortic valve involvement in Behcet's disease. A clinical study of 9 patients. Korean J Internal Med. 2002;17(1):51-6 Available at: https:// www.ncbi.nlm.nih.gov/pmc/articles/PMC4531651/ [Accessed 21 Nov. 2018].

52. Ulusan Z, Karadag A, Tasar M, Kalender D, Osman T. Behcet's disease and cardiovascular involvement: our experience of asymptomatic Behcet's patients : cardiovascular topic. Cardiovasc $J$ Africa. 2014;25(2):63-6 Available at: https://www.ncbi.nlm.nih. gov/pmc/articles/PMC4026764/ [Accessed 21 Nov. 2018].

53. Han J, Kim H, Kim Y, Cho G, Kim M, Sohn D, et al. Behçet's disease as a frequently unrecognized cause of aortic regurgitation: suggestive and misleading echocardiography findings. $J$ Am Soc Echocardiogr. 2009;22(11):1269-74 Available at: http://www. ncbi.nlm.nih.gov/pubmed/19766452 [Accessed 21 Nov. 2018].

54. Xiaoming H, Chengjin H, Yue S, Qian W, Xuejun Z. Clinical analysis of 10 cases of Behcet's disease with prominent heart valve disease. Chin J Med. 2010;90(33):2357-9 Available at: http:// zhyxzz.yiigle.com/CN112137201033/121769.htm?locale=zh_CN [Accessed 21 Nov. 2018].

55. Farouk H. Behçet's disease, echocardiographers, and cardiac surgeons: together is better. Echocardiography. 2014;31(6):783-7 Available at: http://onlinelibrary.wiley.com/doi/full/10.1111/echo. 12524 [Accessed 21 Nov. 2018].

56. Yang H, Ma Y, Luo M, Zhao K, Zhang Y, Zhu G, et al. Identification of gross deletions in FBN1 gene by MLPA. Human
Genom. 2018;12(1):46. https://doi.org/10.1186/s40246-018-0178y. Springer Nature America, Inc, https://www.ncbi.nlm.nih.gov/ pubmed/30286810.

57. Grewal N, Adriana C. Gittenberger-de Groot. Pathogenesis of aortic wall complications in Marfan syndrome. Cardiovasc Pathol. 2018;33:62-9. https://doi.org/10.1016/j.carpath.2018.01.005 Elsevier BV, https://www.ncbi.nlm.nih.gov/pubmed/29433109.

58. Li J, et al. Gross deletions in FBN1 results in variable phenotypes of Marfan syndrome. Clin Chim Acta. 2017;474:54-9. https://doi.org/ 10.1016/j.cca.2017.08.023 Elsevier BV, https://www.ncbi.nlm.nih. gov/pubmed/28842177.

59. Landis BJ, et al. Genotype-phenotype correlations in Marfan syndrome. Heart. 2017;103(22):1750-2. https://doi.org/10.1136/ heartjnl-2017-311513 BMJ, https://heart.bmj.com/content/heartjnl/ 103/22/1750.full.pdf.

60. Dale M, et al. Premature aortic smooth muscle cell differentiation contributes to matrix dysregulation in Marfan syndrome. PLoS One. 2017;12(10):e0186603. https://doi.org/10.1371/journal.pone. 0186603 Public Library Of Science (Plos), https://www.ncbi.nlm. nih.gov/pubmed/29040313.

61. Takeda N, et al. Pathophysiology and management of cardiovascular manifestations in Marfan and Loeys-Dietz syndromes. Int Heart J. 2016;57(3):271-7. https://doi.org/10.1536/ihj.16-094 https:// www.jstage.jst.go.jp/article/ihj/57/3/57_16-094/_article.

62. Lu X-X, et al. Marfan syndrome with a homozygous FBN1 splicing mutation. Am J Med Genet A. 2017;173(9):2435-8. https://doi.org/ 10.1002/ajmg.a.38278 Wiley, https://www.ncbi.nlm.nih.gov/ pubmed/28636274.

63. Franken R, et al. Relationship between fibrillin-1 genotype and severity of cardiovascular involvement in Marfan syndrome. Heart. 2017;103(22):1795-9. https://doi.org/10.1136/heartjnl2016-310631 BMJ, https://heart.bmj.com/content/103/22/1795. long.

64. Cook JR, Carta L, Galatioto J, Ramirez F. Cardiovascular manifestations in Marfan syndrome and related diseases; multiple genes causing similar phenotypes. Clin Genet. 2014;87(1):11-20. https://doi.org/10.1111/cge.12436.

65. Renard M, et al. Sex, pregnancy and aortic disease in Marfan syndrome. PLoS One. 2017;12(7):e0181166. https://doi.org/10.1371/ journal.pone.0181166 Public Library Of Science (Plos), https:// www.ncbi.nlm.nih.gov/pubmed/28708846.

66. Detaint D, Faivre L, Collod-Beroud G, Child AH, Loeys BL, Binquet $\mathrm{C}$, et al. Cardiovascular manifestations in men and women carrying a FBN1 mutation. Eur Heart J. 2010;31(18):2223-9 https://academic.oup.com/eurheartj/article/31/18/2223/484411.

67. Franken R, Groenink M, de Waard V, Feenstra HM, Scholte AJ, van den Berg MP, et al. Genotype impacts survival in Marfan syndrome. Eur Heart J. 2016. https://academic.oup.com/eurheartj/article/37/ 43/3285/2658435.

68. Bitterman AD, Sponseller PD. Marfan syndrome. J Am Acad Orthop Surg. 2017;25(9):603-9. https://doi.org/10.5435/jaaos-d16-00143 Ovid Technologies (Wolters Kluwer Health), https:// www.ncbi.nlm.nih.gov/pubmed/28837453.

69. Baumgartner H, Falk V, Bax J, De Bonis M, Hamm C, Holm PJ, et al. ESC/EACTS Guidelines for the management of valvular heart disease. Eur Heart J. 2017;38(36):2739-91. https://doi.org/10. 1093/eurheartj/ehx391.

70. Lacro RV, Dietz HC, Sleeper LA, et al. Pediatric heart network investigators: atenolol versus losartan in children and young adults with Marfan's syndrome. N Engl J Med. 2014;371(22):2061-71.

71. Shirley E, DeMaio M, Bodurtha J. Ehlers-Danlos syndrome in orthopaedics. Sports Health: Multidiscip Approach. 2012;4(5): 394-403 Available at: https://www.ncbi.nlm.nih.gov/pmc/articles/ PMC3435946/ [Accessed 20 Jul. 2019.

72. Wunderlich C, Schulze M, Strasser R (2004) Severe aortic regurgitation in Ehlers-Danlos syndrome type IV. BMJ, [online] 91(1). 
Available at: http://heart.bmj.com/content/91/1/126 [Accessed 16 Feb. 2019].

73. Melis D, Cappuccio G, Ginocchio V, Minopoli G, Valli M, Corradi $\mathrm{M}$, et al. Cardiac valve disease: an unreported feature in Ehlers Danlos syndrome arthrocalasia type? Ital J Pediatr. 2012;38(1):65 Available at: http://www.ncbi.nlm.nih.gov/pmc/articles/ PMC3545852/ [Accessed 16 Feb. 2019].

74. Takano H, Miyamoto Y, Sawa Y, Fukushima N, Matsumiya G, Fujita T, et al. Successful mitral valve replacement in a patient with Ehlers-Danlos syndrome type VI. Ann Thorac Surg. 2005;80(1): 320-2 Available at: http://www.annalsthoracicsurgery.org/article/ S0003-4975(04)00757-X/pdf [Accessed 16 Feb. 2019].

75. Zainal A, Hamad M, Naqvi S. Dilated aortic root and severe aortic regurgitation causing dilated cardiomyopathy in classic EhlersDanlos syndrome. BMJ Case Reports p.bcr2016215943. 2016 Available at: http://file://CC:/Users/RetailAdmin/Downloads/EDcase-report\%20(1).pdf [Accessed 16 Feb. 2019].

76. Eagleton MJ. Arterial complications of vascular Ehlers-Danlos syndrome. J Vasc Surg https://doi.org/10.1016/j.jvs.2016.06.120. 2016;64:1869-80.

77. Zucker EJ. Syndromes with aortic involvement: pictorial review. Cardiovasc Diagn Ther. 2018;8(Suppl 1):S71-81. https://doi.org/ 10.21037/cdt.2017.09.14

78. Coulon C. Thoracic aortic aneurysms and pregnancy. Presse Med. 2015;44(11):1126-35. Elsevier BV. https://doi.org/10.1016/j.lpm. 2015.02.024.
79. Jondeau G, Boileau C. Genetics of thoracic aortic aneurysms. Curr Atheroscler Rep. 2012;14(3):219-26. https://doi.org/10.1007/ s11883-012-0241-4 Springer Nature, https://www.ncbi.nlm.nih. gov/pubmed/22415348

80. Böckler D, et al. Endovascular treatment of genetically linked aortic diseases. Gefässchirurgie. 2017;22(S1):1-7. https://doi.org/10. 1007/s00772-016-0221-z Springer Nature, https://www.ncbi.nlm. nih.gov/pubmed/28715511.

81. Tran-Fadulu V, Pannu H, Kim DH, Vick GW, Lonsford CM, Lafont $\mathrm{AL}$, et al. Analysis of multigenerational families with thoracic aortic aneurysms and dissections due to TGFBR1 or TGFBR2 mutations. J Med Genet. 2009;46:607-13.

82. Krohg-Sørensen K, et al. Cardiovascular surgery in Loeys-Dietz syndrome types 1-4. Eur J Cardiothorac Surg. 2017;52(6):112531. Oxford University Press (OUP). https://doi.org/10.1093/ejcts/ ezx147.

83. Liu RH, et al. Pseudoaneurysm formation after valve sparing root replacement in children with Loeys-Dietz syndrome. J Card Surg. 2018;33(6):339-43. Wiley. https://doi.org/10.1111/jocs.13709.

84. Valo J, et al. Expanding indications for valve-sparing aortic root reconstruction: early and midterm results. Ann Thorac Surg. 2013;95(2):579-85. Elsevier BV. https://doi.org/10.1016/j. athoracsur.2012.08.079.

Publisher's Note Springer Nature remains neutral with regard to jurisdictional claims in published maps and institutional affiliations. 